\title{
Introduction: Narrative in Psychotherapy:
} The Emerging Metaphor

\author{
Paulo P. P. Machado and Óscar F. Gonçalves \\ Universidade do Minho
}

For the last decade a new metaphor has been progressively, but securely, penetrating the domains of academic and professional psychology. The "narrative" metaphor began to be widely diffused in books, journal articles, and conference papers.

Even though some ancient roots of the narrative metaphor can be traced back (c.f., Polkinghorne, 1988), we are indebted to Theodore Sarbin (1986) for introducing narrative as the alternative "root metaphor" for psychology. It is interesting to note that Sarbin acknowledged the centrality of narrative on both his academic and clinical life:

In my teaching of abnormal psychology, I had found it more useful to report on and analyze life histories, that is, stories about concrete individuals, than to overview the experiments done on nameless, faceless subjects, the results of which were expressed as probabilities. Further, in my role as clinician, I could not carry out my work unless I located the clients and their significant others in a narrative plot (p. IX-X).

Sarbin's statement introduces two themes that are going to be central in the development of the narrative metaphor: narrative as a way of understanding human experience and narrative as a clinical tool. After decades of separation, some academics and practitioners are finally finding a common metaphor for understanding and promoting human change.

Jerome Bruner (1986) is credited for claiming that human beings need to be understood as creators of meanings, and that narrative thought is the process by which this meaning is originated, developed, and changed. Language, in general, and narrative, in particular, finally were accessing the status of psychological phenomena in its own right. Harré and Gillet (1994, p. 26) referred to this movement as the "second cognitive revolution" to illustrate the idea that the "subject is discursive in that he or she uses symbols whose meaning is a function of their use in discourse."

Psychotherapy was not only affected by the narrative movement but became a central vehicle for the diffusion of the narrative metaphor. Clinicians soon realized that narrative

Correspondence concerning this article should be addressed to Paulo P. P. Machado, Universidade do Minho, Departamento de Psicologia, Campus de Gualtar, P-4710 BRAGA, PORTUGAL; e-mail: pmachado@iep. uminho.pt 
was at the very heart of their own work. As was well pointed out by Russell and Wandrei (1996, p. 317), "given the fact that humans use language, and specifically narrative, in the most basic to the most complex meaning making activities, it comes as no surprise that clinical psychologists use narrative in almost all aspects of assessment and intervention."

The popularity of the narrative metaphor in the psychotherapeutic movement is illustrated by the diversity of narrative formulations in psychodynamic, systemic, cognitive, and constructivist therapies (c.f. McLeod, 1997). Common to most of these approaches is the idea, highlighted by Rosen (1996, p. 24), that "the task of therapy is to assist clients in revising their old stories and in constructing new ones that have more relevance and meaning for their current and future lives."

Along with these developments, psychotherapy research began to pay close attention to the role played by narratives in the psychotherapeutic processes. In this issue we have put together several research programs that are currently investigating the role of narrative in psychotherapy. Some of these research programs are more descriptive, while some venture a prescriptive attitude. In any case, we believe that all of them have made important contributions to our current understanding of the role of narrative in psychotherapy.

In the first paper, Pennebaker and Segal (1999) present a summary of their research program in which they ask people to write about personal experiences in an emotional way. This simple task brings improvements both in mental and physical health measures. This research program suggests that the formation of a narrative is crucial and helps to organize complex emotional experiences.

Crits-Christoph, Connolly, and Shaffer (1999) present the reliability and base rates of the interpersonal contents of narratives told in psychotherapy. The authors examine and rate the interpersonal narratives presented by 60 opiate-dependent and 72 depressed patients. Using a comprehensive system based on the circumplex model involving 104 categories, the authors find that most categories can be reliably rated. The authors also report that, although there are some differences between the interpersonal content of depressed and opiate-dependent patient narratives, a number of specific kinds of interpersonal themes occur in most patients in psychotherapy. Further analysis suggests that neither the type of treatment nor therapist are responsible for the interpersonal content of the narratives that patients told in psychotherapy.

Stiles, Honos-Webb, and Lani (1999) present the evolution and the three current formulations of the assimilation model: 1) the Schema formulation; 2) the Voices Formulation; and 3) the Cognitive Science Formulation. In the first formulation, positive therapeutic change is achieved by assimilating problematic experience into the client's schemas. In the voice formulation, assimilation is viewed as a dialogue between a dominant and a problematic voice where a meaning bridge is established. Finally, in the Cognitive Science formulation assimilation is viewed as a process by which different types of memories and memory strategies become linked. The authors suggest that narratives play different roles at the different levels of assimilation process of problematic experiences. This point is illustrated with several clinical transcripts.

Angus, Levitt, and Hardtke (1999) present the Narrative Process Model of therapy and the coding system developed to identify and empirically validate the components of the model. According to the Narrative Process Model, the course of a successful psychotherapeutic process entails exploration, elaboration, and transformation of the client's life stories, which are reflected in thematic macronarratives. The model predicts that this is accomplished through three different modes of inquiry: 1) External Narrative Mode, which entails the description of external events; 2) Internal Narrative Mode, which entails the description and elaboration of the subjective experience; and 3) Reflexive Narrative Mode, which entails the reflexive analysis of both the event (external) and the client's 
reaction (internal) where meaning is addressed. In this paper the authors also present the Narrative Process Coding System, discuss its components, and illustrate its application with clinical examples. Finally, the authors summarize the main research findings of their research program and discuss its implications for psychotherapy practice.

Gonçalves and Machado (1999) present a summary of the research on narrative process in psychotherapy and draw its implications for the development of a cognitive narrative approach to psychotherapy. A model of cognitive-narrative psychotherapy is presented and briefly illustrated. Finally, some data drawn from research projects carried on under this approach are presented and discussed.

Finally, Hermans (1999) presents a theory of meaning construction and reconstruction. The author presents his self-confrontational method and discusses its use in the context of psychotherapy. This method is an idiographic method for self investigation based on the author's valuation theory. This method, which serves both as an assessment and therapy method, allows the client to participate in close collaboration with the therapist in a process of self investigation on the content and organization of their personal meaning. The paper is illustrated with a clinical example.

As stated above, "narrative" has been a proximal zone for the construction of knowledge for both the scientist and the practitioner. We believe that, altogether, these papers shed some light on the implications of narrative approaches to the understanding and practice of psychotherapy. We hope that the reader will be inspired to overcome the subtle frontier between clinical theory, research, and practice, and venture into the role of writer of her/his own experience.

\section{References}

Angus, L., Levitt, H., \& Hardtke, K. (1999). The narrative processes coding system: Research applications and implications for psychotherapy practice. Journal of Clinical Psychology, 55, $1255-1270$.

Bruner, J. (1986). Actual minds possible worlds. Cambridge, MA: Harvard University Press.

Crits-Christoph, P., Connolly, M.B., \& Shaffer, C. (1999). Reliability and base rates of interpersonal themes in narratives from psychotherapy sessions. Journal of Clinical Psychology, 55, $1227-1242$.

Gonçalves, Ó.F., \& Machado, P.P.P. (1999). Cognitive narrative psychotherapy: Research foundations. Journal of Clinical Psychology, 55, 1179-1191.

Harré, R., \& Gillet, G. (1994). The discursive mind. London: Sage.

Hermans, H.J.M. (1999). Self-narrative as meaning construction: The dynamics of self-investigation. Journal of Clinical Psychology, 55, 1193-1211.

McLeod, J. (1997). Narrative and psychotherapy. London: Sage.

Pennebaker, J.W., \& Seagal, J.D. (1999). Forming a story: The health benefits of narrative. Journal of Clinical Psychology, 55, 1243-1254.

Polkinghorne, D. (1988). Narrative knowing and the human sciences. New York: SUNY Press.

Rosen, H. (1996). Meaning-making narratives: Foundations for constructivist and social constructionist psychotherapies. In H. Rosen \& K. Kuehlwein (Eds.), Constructing realities (pp. $3-$ 54). San Francisco: Jossey-Bass.

Russell, R.L. \& Wandrei, M.L. (1996). Narrative and the process of psychotherapy: Theoretical foundations and empirical support. In H. Rosen \& K. Kuehlwein (Eds.), Constructing realities (pp. 307-336). San Francisco: Jossey-Bass.

Sarbin, T. (Ed.) (1986). Narrative psychology: The storied nature of human conduct. New York: Praeger.

Stiles, W.B., Hones-Webb, L., \& Lani, J.A. (1999). Some functions of narrative in the assimilation of problematic experiences. Journal of Clinical Psychology, 55, 1213-1226. 